Technical Note

\title{
Field Evaluation of the Nutrient Removal Performance of a Gross Pollutant Trap (GPT) in Australia
}

\author{
Peter Nichols ${ }^{*}{ }^{\dagger}$ and Terry Lucke ${ }^{\dagger}$ \\ Stormwater Research Group, University of the Sunshine Coast, 90 Sippy Downs Drive, \\ Sippy Downs, 4558 QLD, Australia; tlucke@usc.edu.au \\ * Correspondence: pnichols@usc.edu.au; Tel.: +61-7-5420-8727 \\ + These authors contributed equally to this work. \\ Academic Editor: Marc A. Rosen \\ Received: 29 March 2016; Accepted: 8 July 2016; Published: 14 July 2016
}

\begin{abstract}
Field testing of a proprietary stormwater treatment device (GPT) was undertaken over a one year period at a commercial site located in Sippy Downs, Queensland. The focus of the study was primarily on evaluating the effectiveness of the GPT device in removing pollution in the form of nutrients (Total Suspended Solids, Total Nitrogen, Total Phosphorus) from stormwater runoff. Water quality analysis was performed on water samples taken from the inflow and outflow of the GPT during 15 natural rainfall events. A new testing protocol was developed to ensure a comprehensive investigation of the stormwater treatment performance of the GPT. Pollution treatment Efficiency Ratios (ER) calculated for the GPT were found to be $49.2 \%$ for TSS, $26.6 \%$ for TN and $40.6 \%$ for TP. Although the nutrient removal rates of the GPT observed in the study were below those specified by Queensland regulations, the results are considered notable for a stormwater treatment device that was not specifically designed to remove nutrients from stormwater.
\end{abstract}

Keywords: stormwater pollution; gross pollutant trap; nitrogen; phosphorus; suspended solids

\section{Introduction}

The increase in impervious surface area associated with urban development has resulted in greater stormwater runoff volumes and increased pollution loads for downstream receiving waters [1-3]. The management of stormwater in urban areas has therefore become a priority issue for the planning, construction and maintenance of urban developments [4].

A wide range of stormwater treatment devices (including swales, bioretention systems and constructed wetlands) have been implemented in urban areas over the last few decades to manage stormwater and to reduce peak flows and downstream pollution loads [5,6]. Compared to some more conventional stormwater treatment approaches, which can often be quite complex, proprietary treatment devices are designed for easy installation and maintenance. These devices are becoming ever-more popular in Australia, as well as throughout the rest of the world [7,8]. There has been a range of studies that have focused on the performance and evaluation of conventional treatment devices. However, because proprietary stormwater treatment devices are generally constructed by different companies, only a few independent studies have reviewed their performance [9,10].

Gross pollutant traps (GPT) are one type of proprietary stormwater treatment device that have been widely used for the primary treatment of stormwater runoff in urban catchments. GPTs are designed to remove gross pollutants (litter and sediment larger than $5 \mathrm{~mm}$ in size) [11-13] from stormwater runoff to prevent them from being transported to downstream receiving waters. Although not specifically designed to remove nutrients such as nitrogen and phosphorous from stormwater, GPTs may also reduce the concentrations of these pollutants. 
In order to evaluate the pollutant removal capacity of the GPT system, a field monitoring program was developed and implemented at the University of the Sunshine Coast in 2011. The objective of the study was to evaluate the water quality improvement performance of a Humegard ${ }^{\circledR}$ (Humes, Brisbane, Australia) HG27 during real rainfall events, and to verify its effectiveness in relation to solids, total nitrogen (TN) and total phosphorous (TP) removal. This paper outlines the testing methodology used in the study and presents the study results.

\section{Methodology}

\subsection{Pollutant Trap Description}

One type of manufactured GPT is the Humegard ${ }^{\circledR}$. It uses screening as the dominant mechanism to trap gross pollutants, while its supplementary sedimentation and filtration capabilities are claimed to also effectively remove pollutants including total suspended solids (TSS), nutrients, hydrocarbons and heavy metals (Figure 1). The GPT incorporates a unique floating boom and a storage chamber to allow continual capture of floating material, even during peak flows. The GPT is designed to be installed within stormwater drainage systems, and in retrofit circumstances installation is constrained by flat grades, and low head availability. The floating boom is designed to divert floating matter into the storage chamber at most normal flow ranges. In order to minimise potential upstream backwater effects, the flow can bypass the chamber and flow directly under the boom to the outlet during major rainfall events.

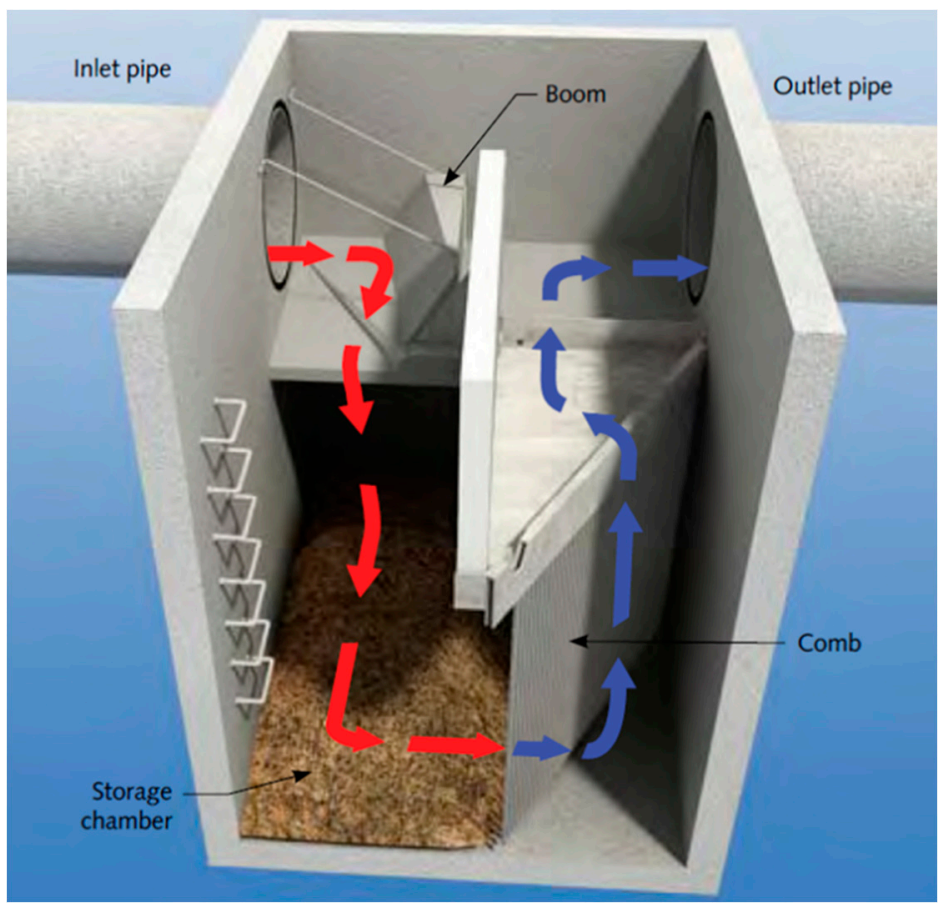

Figure 1. Schematic of a Humegard ${ }^{\circledR}$ GPT system showing flow of stormwater and treatment processes (Humes).

A comprehensive study by Phillips [14] effectively demonstrated the pollution removal of the Humegard ${ }^{\circledR}$ GPT system with respect to gross pollutants and sediment, however, there have been no studies to date that have focused on the nutrient removal performance of the system. This is necessary for a more complete understanding of the pollution removal performance of the GPT device. 


\subsection{Catchment Characteristics}

Testing was undertaken over a period of 2 years at a commercial site in Sippy Downs, approximately $100 \mathrm{~km}$ north of Brisbane, Australia. The catchment drainage area consists of sealed car parks (50\%), building roofs (35\%), and approximately $15 \%$ open space containing lawns and intermittent impervious paved surfaces (concrete pathways). Approximately $85 \%$ of the total catchment area is impervious. The open spaces consist mainly of grassed areas with minimal vegetation, such as small sedges (Carex appressa) in the car park dividers, and a few isolated Paperbark trees (Melaleuca quinquenervia). The site possesses sandy-clay type soil with generally level topography (slope $1 \%-4 \%$ ).

The GPT was positioned to treat the runoff generated from a 6 ha sub-catchment that drains into the Mooloolah River National Park (Figure 2). The average annual rainfall of the study catchment area is approximately $1650 \mathrm{~mm}$ [15] with the greatest proportion generated during spring and summer months (September-February) from high intensity rainfall events.

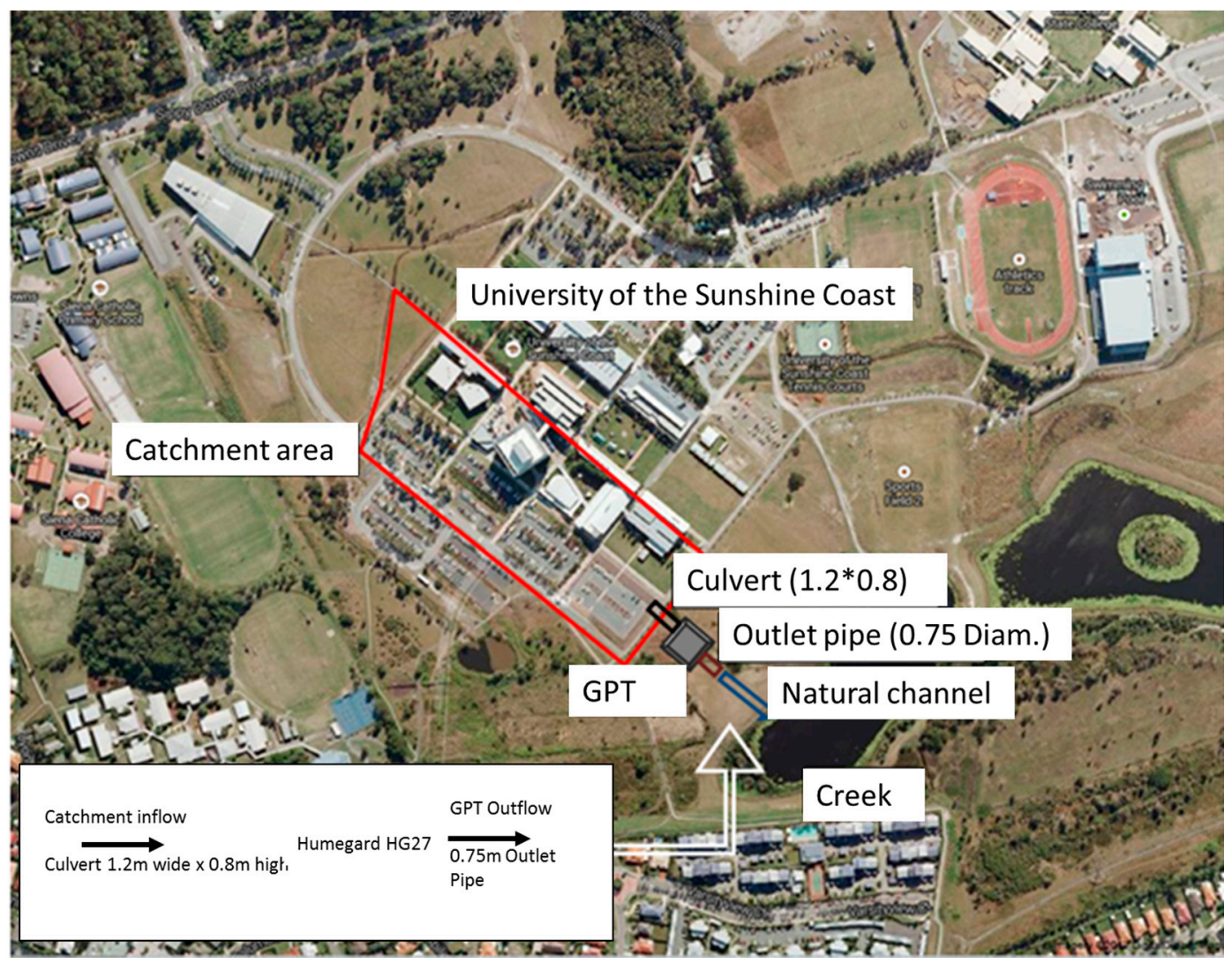

Figure 2. Study catchment at the University of the Sunshine Coast, Sippy Downs.

The catchment characteristics (Figure 3) included a series of grassy slopes $(1 \%-3 \%)$, rock swales, impervious concrete surfaces and drains, and carparks, leading to an underground pipe, which directly feeds into the GPT.

The GPT was installed in December, 2011 and after initial commissioning of the unit, was monitored from June 2013 to March 2014. The Humegard ${ }^{\circledR}$ GPT has been specifically designed to capture up to $85 \%$ of TSS greater than 150 microns in size [13], and it was thought that much of the nutrient removal performance would be linked to pollution attachment to the sediment captured. 


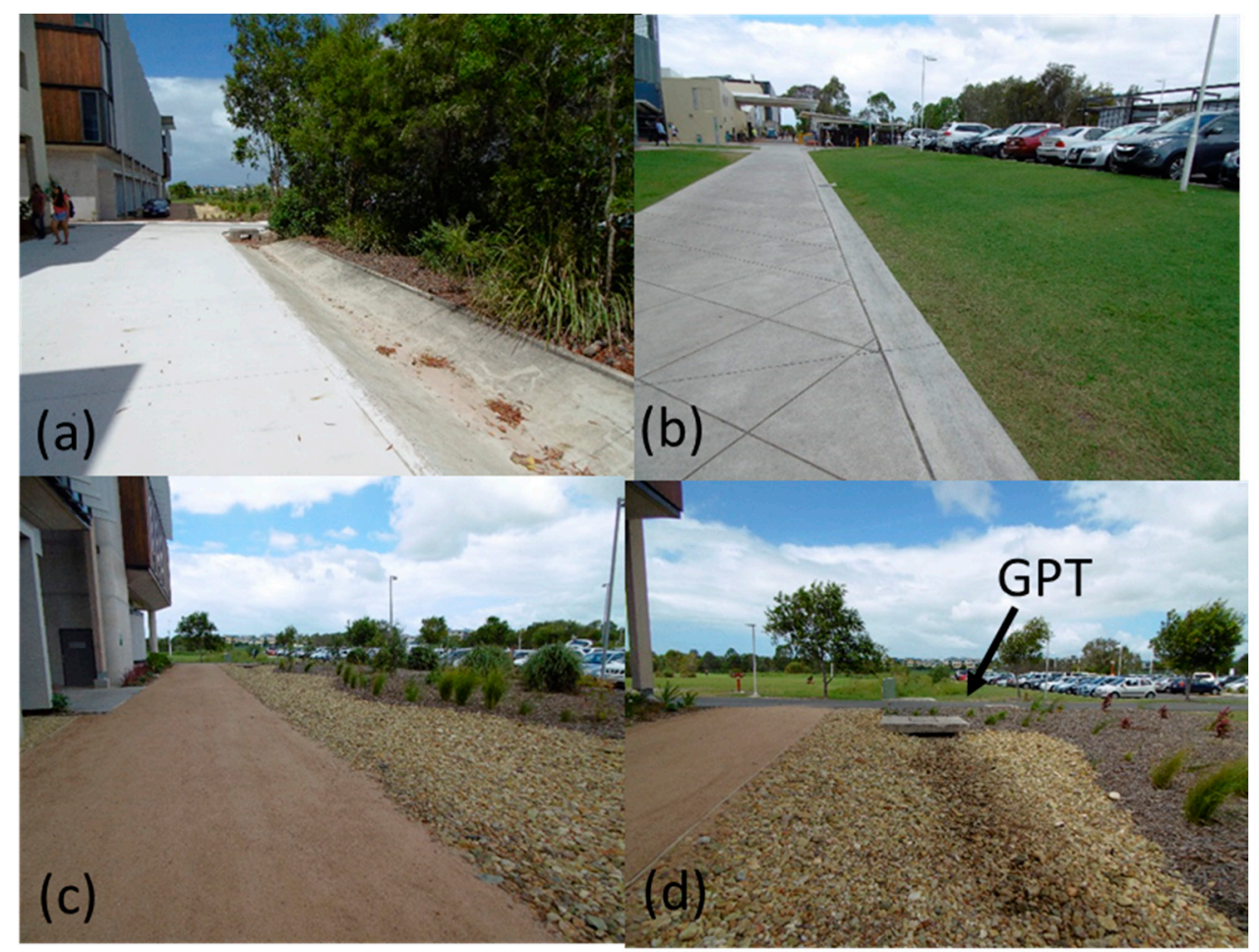

Figure 3. Catchment characteristics: (a) concrete surfaces; (b) carparks and grassy slopes; (c) rock swales; and (d) pit entry to underground pipe (arrow shows GPT location).

The manufacturer recommends that the GPT should be maintained at least annually. However, this is also dependent on observed pollution loads. Maintenance generally includes the removal of sediment from the sump of the unit using a truck-mounted suction hose. The unit was maintained and cleaned directly before the start of this study. However, no maintenance of the unit was undertaken during the test period to ensure that all sediment and nutrients were captured during the study.

\subsection{Sampling Protocol}

A sampling protocol was developed specifically to provide a sufficient number of valid sampling events and water quality samples for analysis (Table 1). These were required to demonstrate the pollution removal performance of the GPT under an appropriate range of natural rainfall and runoff conditions.

The output signals from all the monitoring equipment installed on the GPT in the study were logged using a CR800 Campbell Scientific data logger. Time-weighted subsamples $(200 \mathrm{~mL})$ were taken every $10 \mathrm{~min}$ to provide sampling intervals that would cover at least $60 \%$ of the hydrograph generated by any given rainfall event. A Starflow ultrasonic probe was located in the bypass outlet to measure flowrates through the system. All subsamples collected during runoff events were composited within the automatic sampler storage bottles. Sampling events that collected insufficient volume for the chemical analyses in Table 1 to be undertaken were discarded and recorded as non-qualifying events. These are not included in the results presented in this paper.

The minimum antecedent dry period was set at $24 \mathrm{~h}$ to enable a differentiation between individual rainfall events. This was generally found to be suitable unless the influent pollutant concentrations were found to be below the limits of detection in which case the event was discarded. The minimum event rainfall intensity required to trigger the auto-samplers was set at $2 \mathrm{~mm}$ in $30 \mathrm{~min}$. 
Table 1. Test Methods and Sampling Protocol.

\begin{tabular}{|c|c|c|}
\hline Requirements & Criteria & Details \\
\hline Minimum Qualifying Events & 15 & [16] \\
\hline Minimum Rainfall Intensity & $2 \mathrm{~mm}$ in $30 \mathrm{~min}$ & $\begin{array}{l}\text { Pluviometer (0.2 mm increments) } \\
\text { TB3-Hydrological Services }\end{array}$ \\
\hline Minimum Storm Duration & $15 \mathrm{~min}$ & Necessary to achieve 8 aliquots. \\
\hline Minimum Antecedent Period & $24 \mathrm{~h}$ & [16] \\
\hline $\begin{array}{l}\text { Minimum number and volume } \\
\text { of sample aliquots }\end{array}$ & 8 at $200 \mathrm{~mL}$ & $\begin{array}{l}\text { Composite sample minimum volume } \\
\qquad 1.6 \mathrm{~L}\end{array}$ \\
\hline Sample method & ISCO GLS Auto-samplers & Collected within $4 \mathrm{~h}$ of storm end. \\
\hline Time-weighted samples & Every $10 \mathrm{~min}$ & Starflow ultrasonic probes at pipe outlet \\
\hline Total Suspended Solids (TSS) & APHA (2005) 2540 D & $\begin{array}{l}\text { HDPE or glass bottles, Cool to } 4{ }^{\circ} \mathrm{C} \text {, } \\
\text { maximum hold time } 24 \mathrm{~h}\end{array}$ \\
\hline Total Nitrogen \& TKN & APHA (2005) $4500 \mathrm{~N}$ & $\begin{array}{l}\text { HDPE or glass bottles, Cool to } 4^{\circ} \mathrm{C} \text {, } \\
\text { collect ASAP, maximum hold time } 48 \mathrm{~h}\end{array}$ \\
\hline $\begin{array}{l}\text { Total Phosphorous \& } \\
\text { Orthophosphate }\end{array}$ & APHA (2005) $4500 \mathrm{P}$ & $\begin{array}{l}\text { HDPE or glass bottles, Cool to } 4^{\circ} \mathrm{C} \text {, } \\
\text { collect as soon as possible, maximum } \\
\text { hold time } 48 \mathrm{~h}\end{array}$ \\
\hline Laboratory Certification & $\begin{array}{l}\text { NATA registered for all } \\
\text { parameters except PSD }\end{array}$ & \\
\hline $\begin{array}{l}\text { Quality Assurance/ } \\
\text { Quality Control }\end{array}$ & $\begin{array}{c}\text { Random duplicates and blanks } \\
\text { in accordance with relevant } \\
\text { Australian Standards }\end{array}$ & \\
\hline
\end{tabular}

Notes: APHA: American Public Health Association; NATA: National Association of Testing Authorities, Australia; HDPE: High-density polyethylene; PSD: Particle size distribution.

\subsection{Performance Metrics}

A number of calculation methodologies were used to determine pollution removal performance metrics. These include: Event Mean Concentration (EM-Equation (1)), Average Concentration Removal Efficiency (Avg.CRE—Equation (2)), and Efficiency Ratio (E-Equation (3)) [17-19]. The value of CRE as an effective metric has been reduced as a reliable metric since minor variation $( \pm 1 \mathrm{mg} / \mathrm{L})$ observed in the analytical variability has significant influence on the metric at low influent concentrations, and so ER has been used as the primary metric in this study $[19,20]$. Prior to statistical testing, concentrations of TSS, TN and TP were log transformed (Equation (4)) to achieve normality (Ryan-Joiner $p>0.01$ ). A paired $T$-test was performed on the log-transformed data to calculate if the difference between means was significant [21,22].

Event Mean Concentration (EMC) was calculated using Equation (1):

$$
\mathrm{EMC}=\frac{\sum_{i=1}^{n} V_{i} C_{i}}{\sum_{i=1}^{n} V_{i}}
$$

where,

$V_{i}=$ Volume of flow during period $i$

$C_{i}=$ Concentration associated with period $i$

$n=$ Total number of aliquots collected during event

Average Concentration Removal Efficiency (Avg.CRE) was calculated using Equation (2):

$$
\text { Avg.CRE }=\frac{\sum\left[\frac{E M C_{\text {in }}-E M C_{\text {out }}}{E M C_{\text {in }}}\right]}{\text { no. of events }}
$$


Efficiency Ratio (ER) was calculated using Equation (3):

$$
\mathrm{ER}=\frac{\text { Mean } E M C_{\text {out }}}{\text { Mean } E M C_{\text {in }}}
$$

Log transformation was undertaken using Equation (4):

$$
X^{\prime}=\log _{10}(X+1)
$$

\section{Results and Discussion}

During 10 months of monitoring, 23 rainfall events $(>1.5 \mathrm{~mm})$ were recorded at the study location. Of these, 15 events were characterised as qualifying events according to the agreed sampling protocol (Table 1). The rainfall intensities and durations recorded during the study were typical of those expected on the Sunshine Coast.

The pollution removal performance (CRE) of the GPT for individual rain events ranged between $88.7 \%$ and $5.8 \%$ for TSS, between $-4.0 \%$ and $60.1 \%$ for TN, and between $-17.3 \%$ and $78.3 \%$ for TP (Table 2). Overall pollution removal as calculated by the Efficiency Ratio (ER) for the 15 qualifying rainfall events was $49.2 \%$ for TSS, $26.6 \%$ for TN, and $40.6 \%$ for TP. The highly variable results found in this study are likely to be a result of highly variable, and/or low concentration pollution inflows. This result has also been found in previous studies [19,20,22,23]. Results that were less than the limits of detection (LoD) for that particular test, have been shown as $50 \%$ of the LoD.

Table 2. Measured pollution removal performance using Concentration Reduction Efficiency

\begin{tabular}{|c|c|c|c|c|c|c|c|c|c|c|c|}
\hline Sample & Date & $\begin{array}{l}\text { Rainfall } \\
\text { Depth } \\
(\mathrm{mm})\end{array}$ & $\begin{array}{c}\text { TSS } \\
\text { in } \\
(\mathrm{mg} / \mathrm{L})\end{array}$ & $\begin{array}{c}\text { TSS } \\
\text { out } \\
\text { (mg/L) }\end{array}$ & $\begin{array}{l}\text { TSS \% } \\
\text { Removal }\end{array}$ & $\begin{array}{l}\text { TN in } \\
(\mathrm{mg} / \mathrm{L})\end{array}$ & $\begin{array}{c}\text { TN } \\
\text { out } \\
(\mathrm{mg} / \mathrm{L})\end{array}$ & $\begin{array}{l}\text { TN \% } \\
\text { Removal }\end{array}$ & $\begin{array}{l}\mathrm{TP} \text { in } \\
(\mathrm{mg} / \mathrm{L})\end{array}$ & $\begin{array}{c}\text { TP } \\
\text { out } \\
\text { (mg/L) }\end{array}$ & $\begin{array}{c}\text { TP \% } \\
\text { Removal }\end{array}$ \\
\hline \multicolumn{3}{|c|}{ Limit of Detection (LoD) } & \multicolumn{3}{|c|}{1} & \multicolumn{3}{|c|}{0.1} & \multicolumn{3}{|c|}{0.005} \\
\hline 1 & 12 June 2013 & 80 & 247 & 28 & 88.7 & 0.846 & 0.543 & 35.8 & 0.167 & 0.081 & 51.5 \\
\hline 2 & 17 November 2013 & 42 & 300 & 280 & 6.7 & 0.647 & 0.661 & -2.2 & 0.056 & 0.062 & -10.7 \\
\hline 3 & 18 November 2013 & 9 & 233 & 113 & 51.5 & 0.772 & 0.688 & 10.9 & 0.256 & 0.243 & 5.1 \\
\hline 5 & 30 November 2013 & 15 & 32 & 23 & 28.1 & 0.570 & 0.593 & -4.0 & 0.074 & 0.055 & 25.7 \\
\hline 6 & 11 December 2013 & 14 & 19 & 14 & 26.3 & 1.089 & 1.068 & 1.9 & 0.072 & 0.070 & 2.8 \\
\hline 7 & 6 January 2014 & 21 & 55 & 40 & 27.3 & 0.432 & 0.398 & 7.9 & 0.094 & 0.081 & 13.8 \\
\hline 8 & 8 January 2014 & 1 & 27 & 8 & 70.4 & 2.052 & 1.365 & 33.5 & 0.971 & 0.320 & 67.0 \\
\hline 9 & 16 January 2014 & 6 & 67 & 10 & 85.1 & 0.525 & 0.385 & 26.7 & 0.185 & 0.078 & 57.8 \\
\hline 10 & 22 February 2014 & 10 & 28 & 20 & 28.6 & 1.096 & 0.709 & 35.3 & 0.149 & 0.090 & 39.6 \\
\hline 15 & 27 March 2014 & 130 & 38 & 28 & 26.3 & 0.911 & 0.640 & 29.8 & 0.542 & 0.636 & -17.3 \\
\hline
\end{tabular}
(CRE) values.

The Paired T-test found TSS, TN and TP inflows were significantly reduced after treatment (as measured by outflow pollution concentrations) by the Humegard ${ }^{\circledR}$ HG27 system (Table 3).

The Humegard ${ }^{\circledR}$ GPT system has been specifically designed to remove gross pollutants and Phillips [14] demonstrated that the device can successfully achieve this objective. However, the primary focus of this study was quantification of the solids, and nutrient (TN, TP) pollution removal performance of the system. As anticipated, the overall solids and nutrient removal performance (49.2\% for TSS, $26.6 \%$ for TN and $40.6 \%$ for TP) for the 15 qualifying rainfall events, as calculated by the Efficiency Ratio (ER), was below the minimum values recommended in the regulations [24]. However, these results are particularly impressive for a stormwater treatment device that was not specifically designed to capture nutrients. 
Table 3. Paired T-test for TSS, TN and TP (log transformed).

\begin{tabular}{cccc}
\hline & TSS & TN & TP \\
\hline Mean difference & 0.294 & 0.226 & 0.1341 \\
T value & 4.01 & 4.03 & 4.12 \\
$p$-value & $0.001 *$ & $0.001 *$ & $0.001 *$ \\
alpha & 0.05 & 0.05 & 0.05 \\
\hline & Note: * Significantly different.
\end{tabular}

\section{Conclusions}

Evaluation of proprietary stormwater treatment devices has been performed for decades internationally, and this now appears to be gaining momentum in Australia. While a number of existing guidelines stipulate that performance of these devices must be demonstrated for local and regional conditions, the guidelines generally do not define exactly how this should be accomplished.

This paper has detailed the evaluation and testing protocol implemented of the Humegard ${ }^{\circledR}$ HG27 GPT at one monitoring site in Queensland, Australia. Results from 15 complying rainfall events showed a pollution removal efficiency (ER) for the GPT of $49.2 \%$ for TSS, $26.6 \%$ for TN and $40.6 \%$ for TP. Based on the water quality analyses undertaken in the study, concentrations of TSS, TN and TP were all found to be significantly reduced after treatment by the GPT device.

To complement the recognised capability of the Humegard ${ }^{\circledR} \mathrm{HG} 27$ to remove gross pollutants, this study found the system also made a positive contribution to the removal of TSS and nutrient pollution from stormwater flows. Although the concentration removal rates of TN and TP by the GPT did not achieve the minimum regulated standards, the results are still impressive for a stormwater treatment device that was not specifically designed to capture nutrients. It is suggested that additional components would need to be added in the form of a treatment train to fully satisfy the specific Queensland Government regulations in terms of TSS, TN and TP pollution removal.

Acknowledgments: The authors acknowledge the contribution to this research by Humes Water Solutions Australia, and Michael Neilsen and Ronald Kleijn from the University of the Sunshine Coast.

Author Contributions: Both authors have contributed equally to the preparation of this article.

Conflicts of Interest: The authors declare no conflict of interest.

\section{References}

1. Dietz, M.E. Low Impact Development Practices: A Review of Current Research and Recommendations for Future Directions. Water Air Soil Pollut. 2007, 186, 351-363. [CrossRef]

2. Lucke, T.; Beecham, S. Field Investigation of Clogging in a Permeable Pavement System. J. Build. Res. Inf. 2011, 39, 603-615. [CrossRef]

3. Hossain, I.; Imteaz, M.A.; Hossain, M.I. Continuous Simulation of Suspended Sediment through a Stream Section. Int. J. Water 2013, 7, 206-222. [CrossRef]

4. Nichols, P.W.B.; White, R.; Lucke, T. Do sediment type and test durations affect results of laboratory-based, accelerated testing studies of permeable pavement clogging? Sci. Total Environ. 2015, 511, 786-791. [CrossRef] [PubMed]

5. Taylor, A.C.; Wong, T.H.F. Non-Structural Stormwater Quality: Best Management Practices: A Literature Review of Their Value and Life-Cycle Costs; CRC for Catchment Hydrology: Melbourne, Australia, 2002.

6. Davis, A. Field Performance of Bioretention: Hydrology Impacts. J. Hydrol. Eng. 2008, 13, 90-95. [CrossRef]

7. Hipp, J.A.; Ogunseitan, O.; Lejano, R.; Smith, C.S. Optimization of stormwater filtration at the urban/watershed interface. Environ. Sci. Technol. 2006, 40, 4794-4801. [CrossRef] [PubMed]

8. Sample, D.J.; Grizzard, T.J.; Sansalone, J.; Davis, A.P.; Roseen, R.M.; Walker, J. Assessing performance of manufactured treatment devices for the removal of phosphorus from urban stormwater. J. Environ. Manag. 2012, 113, 279-291. [CrossRef] [PubMed] 
9. Arbor, A. Environmental Verification Technology Report: Stormwater Source Area Treatment Device: Baysaver Technologies, Inc.-Baysaver Separation System, Model 10K; Report No. 05/21/WQPC-WWFI; U.S. Environmental Protection Agency: Washington, DC, USA, 2005.

10. Al-Hamdan, A.Z.; Nnadi, F.N.; Romah, M.S. Performance reconnaissance of stormwater proprietary best management practices. J. Environ. Sci. Health A Toxic Hazard Subst. Environ. Eng. 2007, 42, 427-437. [CrossRef] [PubMed]

11. Roesner, L.A.; Pruden, A.; Kidder, E.M. Improved Protocol for Classification and Analysis of Stormwater-Borne Solids; Water Environment Research Foundation: Alexandria, VA, USA, 2007.

12. Allison, R.; Pezzaniti, D. Gross Pollutant and Sediment Traps, in Australian Runoff Quality-A Guide to Water Sensitive Urban Design; Wong, T.H.F., Ed.; Institution of Engineers: Barton, Australia, 2006.

13. Humes Stormwater Solutions, 2016. HumeGard ${ }^{\circledR}$ GPT Technical Manual. Available online: http://www. humes.com.au/uploads/HUMES/HumeGard_technical_manual_Issue_3_March_2015.pdf (accessed on 12 July 2016).

14. Phillips, D.L. Technical Report on the In-Line Litter Separator Installation and Monitoring Project; EcoRecycle Victoria and Swinburne University of Technology: Melbourne, Australia, 1998.

15. Bureau of Meteorology Queensland Weather and Warnings, 2016. Available online: http://www.bom.gov.au (accessed on 21 March 2016).

16. Wong, G. Proprietary Devices Evaluation Protocol (PDEP) for Stormwater Quality Treatment Devices, Version 3; Auckland Regional Council: Auckland, New Zealand, 2012.

17. Strecker, E.W.; Quigley, M.M.; Urbonas, B.R.; Jones, J.E.; Clary, J.K. Determining urban storm water BMP effectiveness. J. Water Resour. Plann. Manag. 2001, 127, 144-149. [CrossRef]

18. McNett, J.K.; Hunt, W.F.; Osborne, J.A. Establishing storm-water BMP evaluation metrics based upon ambient water quality associated with benthic macroinvertebrate populations. J. Environ. Eng. 2010, 136, 535-541. [CrossRef]

19. Lenhart, H.A.; Hunt, W.F. Evaluating four storm-water performance metrics with a North Carolina Coastal Plain storm-water wetland. J. Environ. Eng. 2011, 137, 155-162. [CrossRef]

20. Nichols, P.; Lucke, T.; Drapper, D.; Walker, C. Performance Evaluation of a Floating Treatment Wetland in an Urban Catchment. Water 2016. [CrossRef]

21. Winston, R.J.; Hunt, W.F.; Kennedy, S.G.; Merriman, L.S.; Chandler, J.; Brown, D. Evaluation of floating treatment wetlands as retrofits to existing stormwater retention ponds. Ecol. Eng. 2013, 54, 254-265. [CrossRef]

22. Borne, K.; Fassman-Beck, E.; Winston, R.; Hunt, W.; Tanner, C. Implementation and Maintenance of Floating Treatment Wetlands for Urban Stormwater Management. J. Environ. Eng. 2015, 141, 04015030. [CrossRef]

23. Borne, K.E. Floating treatment wetland influences on the fate and removal performance of phosphorus in stormwater retention ponds. Ecol. Eng. 2014, 69, 76-82. [CrossRef]

24. State of Queensland. State Planning Policy; Department of State Development, Infrastructure and Planning, State of Queensland: Brisbane, Australia, 2014.

(C) 2016 by the authors; licensee MDPI, Basel, Switzerland. This article is an open access article distributed under the terms and conditions of the Creative Commons Attribution (CC-BY) license (http://creativecommons.org/licenses/by/4.0/). 